\title{
A STUDY ON HETEROGENEOUS FENTON REGENERATION OF POWDERED ACTIVATED CARBON IMPREGNATED WITH IRON OXIDE NANOPARTICLES
}

\section{PLAKAS K.V. KARABELAS A.J.}

Received: 15/01/2016

Accepted: 01/03/2016

Available online: 13/04/2016
Chemical Process and Energy Resources Institute Centre for Research and Technology - Hellas P.O. Box 60361, $6^{\text {th }} \mathrm{km}$ Charilaou-Thermi road Thermi, Thessaloniki, GR 57001, Greece

*to whom all correspondence should be addressed: e-mail: kplakas@cperi.certh.gr

\begin{abstract}
This paper reports on the fabrication, characterization and testing of iron oxide nanoparticles - powdered activated carbon (PAC) composites for water treatment and PAC regeneration by Fenton reactions. Different wet impregnation procedures and iron loadings were assessed in terms of organic micropollutant adsorption, by using the pharmaceutical diclofenac (DCF) as model compound. The preparation of a ferrihydrite-impregnated PAC with low iron content $\left(\sim 40.7 \mathrm{mg}_{\mathrm{Fe}} / \mathrm{g}_{\mathrm{PAC}}\right)$ and high BET surface area $\left(1037 \mathrm{~m}^{2} \mathrm{~g}^{-1}\right)$ was found to be the optimum, exhibiting excellent DCF adsorption capacity, similar to that of the original PAC $\left(203 \mathrm{mg} \mathrm{gCF} / \mathrm{g}_{\mathrm{PAC} / \mathrm{Fe}}\right)$, with the adsorption isotherm satisfactorily fitted by both the Freundlich and Langmuir models. The regeneration of the ferrihydrite-PAC (Fe/PAC) indicated that the presence of iron-oxide nanoparticles is important for achieving a high regeneration efficiency by hydrogen peroxide, even at neutral $\mathrm{pH}$. However, the solution $\mathrm{pH}$ had a significant effect on DCF uptake, being greater at acidic $\mathrm{pH}$ after the regeneration of the composite. Ongoing R\&D is aimed at material optimization and testing in a novel hybrid process scheme developed in authors' laboratory, involving a continuous Fe/PAC - Fenton process in conjunction with a low pressure membrane separation process.
\end{abstract}

Keywords: powdered activated carbon adsorption, iron oxide, Fenton regeneration, diclofenac, water purification

\section{Introduction}

Advanced Oxidation Processes (AOP) have emerged as a promising technology for the in-situ regeneration of activated carbons saturated with non-polar (or very low polarity) organic compounds, owing to their potency to degrade these species on site, through the generation of very reactive and non-selective free hydroxyl radicals ( ${ }^{\circ} \mathrm{OH}$ ) at ambient conditions (Zanella et al., 2014; Salvador et al., 2015). The remarkable advantage of AOP over all chemical and biological processes is that they are environment-friendly, as they neither transfer pollutants from one phase to another (as in chemical precipitation and volatilization) nor produce hazardous side-streams (Oller et al., 2011). A common feature of all AOP studied so far for spent $A C$ regeneration is the external addition of $\mathrm{H}_{2} \mathrm{O}_{2}$ as a source of ${ }^{\circ} \mathrm{OH}$ (Bach and Semiat, 2011; Anfruns et al., 2013). Other techniques involve the combination of $\mathrm{H}_{2} \mathrm{O}_{2}$ with other radical promoters, such as $\mathrm{O}_{3}, \mathrm{UV}$ and iron salts (Fenton reaction) (Horng and Tseng, 2008; Bañuelos et al., 2013). However, their commercial use in full-scale treatment plants is limited due to specific drawbacks, including high energy consumption, separation problems of applied suspended catalysts and difficulties of scaling-up (Zanella et al., 2014; Salvador et al., 2015). To address these issues, several research groups have turned their attention to electrochemically based AOP (EAOP) that take advantage of the conductive nature of carbon 
(Weng and Hsu, 2008; Wang and Balasubramanian, 2009; Bañuelos et al., 2013). Specifically, EAOP based on the Fenton reaction chemistry have recently been developed in which $\mathrm{H}_{2} \mathrm{O}_{2}$ (a weak oxidant) can be successfully electro-generated in situ by means of special electrodes and process conditions, which in the presence of transition-metal catalysts, such as iron ions, reacts to form the very powerful ${ }^{\circ} \mathrm{OH}$ oxidants (electro-Fenton/EF) (Brillas et al., 2009). In contrast to other AOP studied in the literature for the regeneration of $\mathrm{AC}, \mathrm{EF}$ has the remarkable advantage of regenerating carbons at near ambient conditions and with no external addition of $\mathrm{H}_{2} \mathrm{O}_{2}$ as a ${ }^{\circ} \mathrm{OH}$ oxidant source with obvious advantages related to $\mathrm{H}_{2} \mathrm{O}_{2}$ cost and safety/handling. Complementary to the electrochemical synthesis of $\mathrm{H}_{2} \mathrm{O}_{2}$, iron-loaded activated carbons can be utilized to promote the presence of the Fenton mixture in solution $\left(\mathrm{Fe}^{2+} / \mathrm{H}_{2} \mathrm{O}_{2}, \mathrm{Fe}^{3+} / \mathrm{H}_{2} \mathrm{O}_{2}\right)$, thus avoiding the use of dissolved Fe salts and increasing the catalytic activity of bare AC for advanced oxidation reactions (Kan and Huling, 2009; Do et al., 2011).

EF studies have mostly focused on the regeneration of granular activated carbons (GAC; in form of fixed bed processes), considering that there is no need for carbon recovery and reuse as in the case of powdered activated carbon (PAC), to allow continuous water treatment. A promising approach for separation and reuse of PAC is the utilization of low pressure membrane processes (ultrafiltration-UF, microfiltration-MF) for carbon separation from treated water (Stoquart et al., 2012). This concept is not new. A number of full-scale PAC/UF plants operate worldwide, while in Europe most are located in France. For example, the l' Apier Saint-Cassien and Vigneaux-sur-Seine plants use the PAC/UF process given the reliability, the performance and increasingly stringent treatment objectives in terms of dissolved organic carbon (DOC) and disinfection byproducts (DBPs) reduction (Clark et al., 1996). In PAC/UF business, the Aquasource system is, today, the only one possessing significant operating experience. In the Natural Resources and Renewable Energies (NRRE) Laboratory at CPERI/CERTH, the concept of catalyst separation has been largely investigated in photocatalytic reactors (Photocatalytic Membrane Reactor-PMR) (Sarasidis et al., 2014) and bioactive solids separation in membrane bioreactor (MBR) wastewater treatment (Patsios and Karabelas, 2011). Moreover, a novel electro-Fenton (EF) device/'filter' was recently developed at the author's laboratory (Plakas et al., 2013; Sklari et al., 2015), in which ${ }^{\circ} \mathrm{OH}$ are produced in situ as a result of Fenton reactions, involving electro-generated $\mathrm{H}_{2} \mathrm{O}_{2}$ and iron-loaded carbon electrodes to promote the presence of the Fenton mixture in solution, thus avoiding the use of dissolved iron salts.

By taking advantage of the above expertise, alternative approaches are developed in the authors laboratory which involve EAOP in conjunction (or not) with low pressure membrane processes. NRRE/CERTH is currently working on the development of a novel hybrid (photo)electro-Fenton/PAC/UF process, combining the advantages of the two AOP, with applications in water treatment/purification and regeneration of PAC saturated/ exhausted by organic pollutants. In this paper, preliminary results are presented of the experimental work performed on the fabrication of composite iron-PAC materials, that enable the heterogeneous Fenton oxidation reactions in the presence of $\mathrm{H}_{2} \mathrm{O}_{2}$. Specifically, batch adsorption/regeneration experiments were carried out with commercial PAC and diclofenac (DCF) as model organic compound; the latter is a widely used non-steroidal anti-inflammatory drug and one of the most frequently detected pharmaceutically active compounds in drinking water sources (groundwater, rivers, lakes) (Loos et al., 2009; Lapworth et al., 2012). The regeneration efficiency was assessed by performing both heterogeneous (Fe-loaded PAC solutions) and homogeneous (dissolved iron salts in PAC solutions) Fenton treatment experiments, with external addition of $\mathrm{H}_{2} \mathrm{O}_{2}$.

\section{Experimental work}

\subsection{Materials and methods}

A commercial powdered activated carbon (DARCO ${ }^{\circ} \mathrm{G} 60$, Sigma-Aldrich) was selected for the scope of this study, exhibiting BET surface area of $1052.9 \pm 3.34 \mathrm{~m}^{2} \mathrm{~g}^{-1}$, total pore volume $0.93 \mathrm{~cm}^{3} \mathrm{~g}^{-1}$ and average pore width $3.0 \mathrm{~nm}$. Diclofenac sodium salt (DCF) was of analytical grade (Sigma-Aldrich) and used as received. 
Extra pure $\mathrm{H}_{2} \mathrm{O}_{2}$ of $30 \%(\mathrm{w} / \mathrm{w})$ (Panreac Química S.A.U) was used as oxidant. Iron (II) chloride tetrahydrate $\left(\mathrm{FeCl}_{2} .4 \mathrm{H}_{2} \mathrm{O}\right.$, Panreac Química S.A.U), iron (III) chloride hexahydrate ( $\mathrm{FeCl}_{3} .6 \mathrm{H}_{2} \mathrm{O}$, Panreac Química S.A.U), iron (III) nitrate nonahydrate $\left(\mathrm{Fe}\left(\mathrm{NO}_{3}\right)_{3} 9 \mathrm{H}_{2} \mathrm{O}\right.$, Merck) and ethanol absolute $\left(\mathrm{CH}_{3} \mathrm{CH} \mathrm{H}_{2} \mathrm{OH}\right.$, Scharlab $\left.\mathrm{SL}\right)$, reagent grade, were used in the preparation of the $\mathrm{PAC} / \mathrm{Fe}$ composites. $\mathrm{FeSO}_{4} 7 \mathrm{H}_{2} \mathrm{O}$ was used for the preparation of the iron solutions used in the homogeneous Fenton oxidation experiments. Table mineral water (Vikos water, $\mathrm{pH} 7.3$, conductivity $\sim 480 \mu \mathrm{sm}^{-1}$, hardness $259 \mathrm{mg} \mathrm{I}^{-1} \mathrm{CaCO}_{3}$ ) was used in all experiments, simulating drinking water with stable anion/cation content. The textural properties of the $\mathrm{PAC}$ and of the PAC/Fe composites were measured by $\mathrm{N}_{2}$ adsorption-desorption (BET analysis) performed at $-196{ }^{\circ} \mathrm{C}$ with a Micromeritics TriStar porosimeter in the relative pressure P/Po range of 0.01 to 0.30 . Their structural properties were determined by X-ray diffraction using a D-500 diffractometer from Bruker equipped with a $\mathrm{Cu} K \alpha$ radiation $(\lambda=1.5418 \AA$ ) source. Phase identification was made through comparison with the JCPDS database. The morphology of the composite materials was examined by SEM, using a JEOL JSM6300 microscope operating at $20 \mathrm{kV}$ (equipped with an X-ray Microanalysis - EDS). The point of zero charge $\left(\mathrm{pH}_{\mathrm{pzc}}\right)$ of the carbon materials was measured by employing the batch equilibrium method described elsewhere (Sklari et al.,2015). The variation of DCF concentration was followed by HPLC/DAD according to the method described elsewhere (Sklari et al., 2015). The concentration of $\mathrm{H}_{2} \mathrm{O}_{2}$ consumed during the experiments was determined photometrically by the iodide method.

Table 1. Preparation procedures of iron-oxide-impregnated PAC adsorbents.

\begin{tabular}{|c|c|c|c|c|}
\hline & Procedure & $\begin{array}{c}\mathrm{PAC} / \mathrm{Fe} \\
\text { composite }\end{array}$ & $\begin{array}{l}\text { Fe capacity } \\
\left(\mathrm{mg}_{\mathrm{Fe}} / \mathrm{g}_{\mathrm{PAC}}\right)^{\mathrm{a}}\end{array}$ & $\mathrm{pH}_{\mathrm{pzc}}$ \\
\hline A & $\begin{array}{l}\text { PAC pretreatment } \\
\text { None } \\
\text { Fe loading } \\
\text { - Addition of PAC (1.0 g) in Erlenmayer flask containing } 100 \mathrm{~mL} \\
\text { Fe( }\left(\mathrm{NO}_{3}\right)_{3} 9 \mathrm{H}_{2} \mathrm{O} 0.01 \mathrm{M}[\mathrm{PAC} / \mathrm{Fe}(1)] \text { or } 0.1 \mathrm{M}[\mathrm{PAC} / \mathrm{Fe}(2)] \text {. } \\
\text { - Stirring for } 120 \mathrm{~min} \text { at } 200 \mathrm{rpm}, 25^{\circ} \mathrm{C} \text { (water cooling system). } \\
\text { - Dropwise addition of } 1.0 \mathrm{M} \mathrm{NaOH} \text { until the solution pH reaches } 7.0-8.0 \text {. } \\
\text { - PAC/Fe separation through Millipore } 0.45 \mu \mathrm{m} \text { and washing with deionized } \\
\text { water to remove the salts. } \\
\text { - Overnight drying in the oven }\left(\sim 100{ }^{\circ} \mathrm{C}\right) \text { and storing of the PAC/Fe } \\
\text { adsorbent in a desiccator for further use. }\end{array}$ & $\mathrm{PAC} / \mathrm{Fe}(2)$ & 776.0 & 7.80 \\
\hline B & $\begin{array}{l}\text { PAC pretreatment } \\
\text { - Cleaning of the PAC with absolute ethanol to remove the impurities from } \\
\text { its surface and then drying at room temperature for } 24 \mathrm{~h} \text { [only for } \\
\text { PAC/Fe(3)]. } \\
\text { Fe loading } \\
\text { - } \mathrm{N}_{2} \text { passing through } 150 \mathrm{~mL} \text { ethanol absolute for about } 1.5 \mathrm{~h} \text { at room } \\
\text { temperature in order to remove the dissolved oxygen. } \\
\text { - Subsequently, } \mathrm{FeCl}_{3} 6 \mathrm{H}_{2} \mathrm{O} \text { and } \mathrm{FeCl}_{2} 4 \mathrm{H}_{2} \mathrm{O} \text { are added in a molar ratio of } 2: 1 \text {, } \\
\text { under continuous stirring and } \mathrm{N}_{2} \text { atmosphere. } \\
\text { - Addition of the PAC ( } 1.0 \mathrm{~g}) \text { in the iron solution, which is slowly stirred for } \\
\text { 1.5 h. } \\
\text { - Drop-wise addition of } 6.8 \mathrm{~mL} \text { ammonia ( } 25 \%) \text {, so that the solution turns } \\
\text { gradually dark. Stirring for } 10 \text { min, treatment in an ultrasonic bath for } \\
\text { another } 10 \text { min, and again stirring overnight under ambient conditions. } \\
\text { - Washing of the PAC/Fe adsorbent with deionized water and treatment } \\
\text { with ethanol in an ultrasonic bath, thus, removing the weakly absorbed } \\
\text { iron species. } \\
\text { - Drying of the PAC/Fe adsorbent at room temperature for } 48 \mathrm{~h} \text { and storing } \\
\text { in a desiccator for further use. }\end{array}$ & $\mathrm{PAC} / \mathrm{Fe}(3)$ & 511.0 & 8.45 \\
\hline
\end{tabular}

a Calculation through iron mass balances (the difference between the iron in the loading solution and the iron removed during the washing step) (photometric measurements at 510nm according to APHA3500-FeB); ${ }^{b}$ The point of zero charge determines the solution $\mathrm{pH}$ for which the electrical charge density on a surface is zero. In case of the bare $\mathrm{PAC}$ the $\mathrm{pH}_{\mathrm{pzc}}$ value was measured 7.38 . 


\subsection{Preparation of iron-oxide-impregnated PAC adsorbents}

Four iron-impregnated PAC adsorbents where prepared, with varied iron loading, according to two different fabrication procedures (Table 1).

Procedure $A$ is similar to that described by Park et al. (2015), with which ferrihydrite (hydrated iron oxide) nanoparticles can be effectively loaded on PAC. Procedure $B$ was adopted from our previous work (Sklari et al., 2015), in which carbon felt samples were successfully impregnated with mixed valence iron oxides $\left(\gamma-\mathrm{Fe}_{2} \mathrm{O}_{3} / \mathrm{F}_{3} \mathrm{O}_{4}\right)$.

\subsection{Experimental procedures}

Batch adsorption tests were carried out by adding PAC or PAC/Fe adsorbents to DCF solutions ( $20 \mathrm{mg} \mathrm{l}^{-1}$ adsorbent: $5 \mathrm{mg} \mathrm{l}^{-1} \mathrm{DCF}$ ) in 1 l Erlenmayer flasks. The solutions were stirred at a constant rate ( $\left.300 \mathrm{rpm}\right)$, allowing sufficient time for adsorption equilibrium. For adsorption isotherm experiments, PAC or $\mathrm{PAC} / \mathrm{Fe}(1)$ (presenting the best DCF adsorption capacity among the PAC/Fe composites prepared) was dissolved in $250 \mathrm{ml}$ Erlenmayer flasks containing different initial concentrations of DCF. The solutions were stirred at $300 \mathrm{rpm}$ for $240 \mathrm{~min}$ and then filtered through Millipore $0.45 \mu \mathrm{m}$ filters. DCF adsorbed was calculated on the basis of mass balances.

Considering the high capacity of PAC and PAC/Fe(1) for DCF adsorption, the experimental protocol for assessing the Fenton regeneration efficiency consisted of three distinct operations: a) initially, adsorbents were saturated with DCF (a ratio $5 \mathrm{mg} \mathrm{l}^{-}$adsorbent : $1 \mathrm{mg} \mathrm{l}^{-1}$ DCF was selected for this step, based on the preceding adsorption tests); b) in continuation, homogeneous Fenton regeneration of saturated PAC at $\mathrm{pH} 3$ (addition of $\mathrm{FeSO}_{4} 7 \mathrm{H}_{2} \mathrm{O}$ and $\mathrm{H}_{2} \mathrm{O}_{2}$ at different molar ratios) or heterogeneous Fenton regeneration of PAC/Fe(1) (addition of $\mathrm{H}_{2} \mathrm{O}_{2}$ ) took place by stirring the solutions at $300 \mathrm{rpm}$ for $\sim 24 \mathrm{~h}$; c) finally, the residual $\mathrm{H}_{2} \mathrm{O}_{2}$ was removed by adding a small quantity of sodium metabisulfite $\left(\mathrm{Na}_{2} \mathrm{~S}_{2} \mathrm{O}_{5}\right)$, afterwards the solution $\mathrm{pH}$ was adjusted to $\sim 7.3$, and a new quantity of DCF was stirred again at $300 \mathrm{rpm}$ for 3-4 $\mathrm{h}$. All experiments were performed at $25^{\circ} \mathrm{C}$ with flasks placed in a water bath with magnetic stirrers. The flasks were plugged and kept closed to avoid the fluctuation of $\mathrm{pH}$ due to the exchange of gases during the experiments. Samples of the reactant mixtures were withdrawn at different reaction times and filtered through Millipore $0.45 \mu \mathrm{m}$ cartridges before their subsequent HPLC/DAD analysis. Experiments were carried out in duplicate and the average values are reported in this study.

\section{Results \& discussion}

\subsection{PAC/Fe adsorbents characterization}

$\mathrm{N}_{2}$ adsorption-desorption measurements showed that the surface area was significantly reduced upon impregnation with iron oxides; although the pore sizes remained almost the same as those of bare PAC (Fig.1a). However, the reduction was not necessarily related to the iron content (Table 1), since PAC/Fe(2) with the higher iron content, presented a larger pore size and a slightly larger surface area than that of $\mathrm{PAC} / \mathrm{Fe}(4)$. Obviously, the textural properties of PAC can be altered to a different extent, depending on the iron-impregnation procedure applied. This is also true for procedure $B$, since the pretreatment of PAC with absolute ethanol [PAC/Fe(3)], resulted in a greater iron loading (Table 1) and a greater surface area (Fig. 1a, inset) in comparison to the non-pretreated one [PAC/Fe(4)].

The XRD patterns show the presence of carbon, silica oxide and iron oxide in the structure of the composite adsorbents (Fig. 1b). Silica oxide is impurity of the initial PAC, whereas the presence of iron oxides confirms the impregnation of iron species $\left(\mathrm{Fe}_{2} \mathrm{O}_{3}, \mathrm{Fe}_{3} \mathrm{O}_{4}\right)$ on the surface of PAC particles. The iron oxides were not easily observed from SEM analysis (Fig. 2a), since the visualized surfaces did not exhibit any distinct differences from that of the bare PAC, suggesting that most of the iron oxide was impregnated in the PAC-particle inner pores, as evidenced by the EDS peaks (Fig. 2b) and the elemental SEM mapping of the samples (not shown here). A similar observation was also made by previous researchers (Do et al., 
2011; Park et al., 2015), according to whom impregnation of iron oxide $\left(\mathrm{Fe}_{3} \mathrm{O}_{4}{ }^{-}\right.$or ferrihydrite-impregnated $\mathrm{PAC}$ ) may not block the mouth and channel of the carbon pores significantly. The $\mathrm{pH}_{\mathrm{pzc}}$ values reported in Table 1 are indicative of an increased dissociation (release of proton, $\mathrm{H}^{+}$) of the functional groups due to the impregnation of iron species on the carbon surface, with an increased acid character at lower $\mathrm{pH}$ values, such as phenol (-OH) and carboxyl $\left({ }^{-} \mathrm{COOH}\right)$.
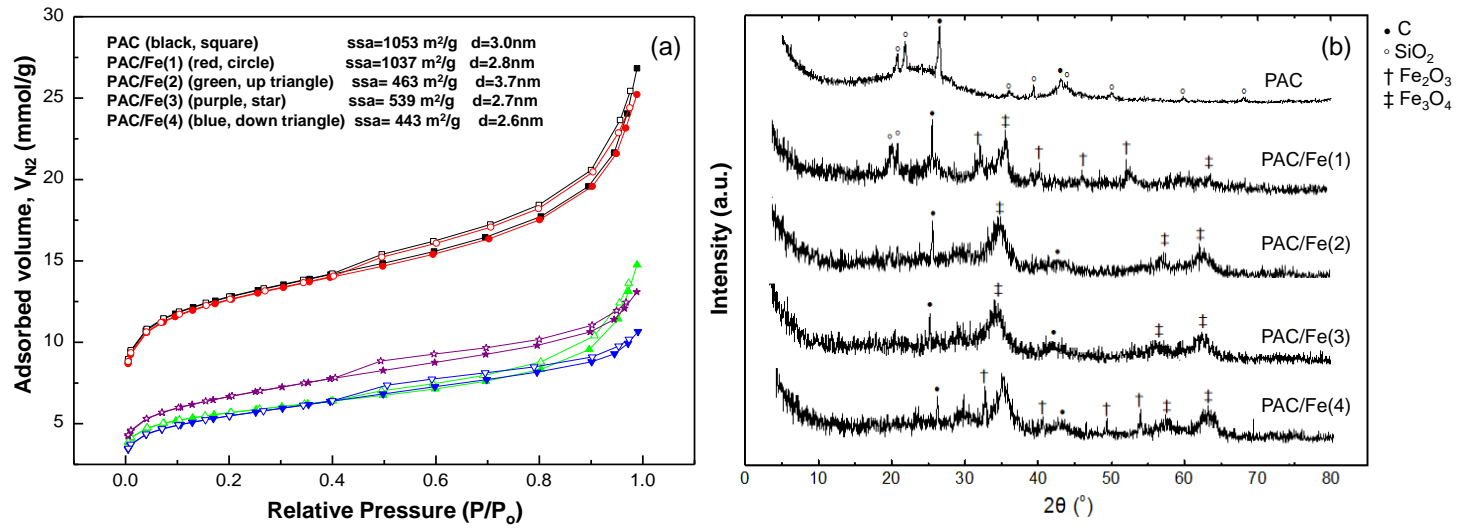

Figure 1. (a) Nitrogen adsorption-desorption isotherms, and (b) XRD patterns, of bare PAC and ironoxide-impregnated PAC adsorbents
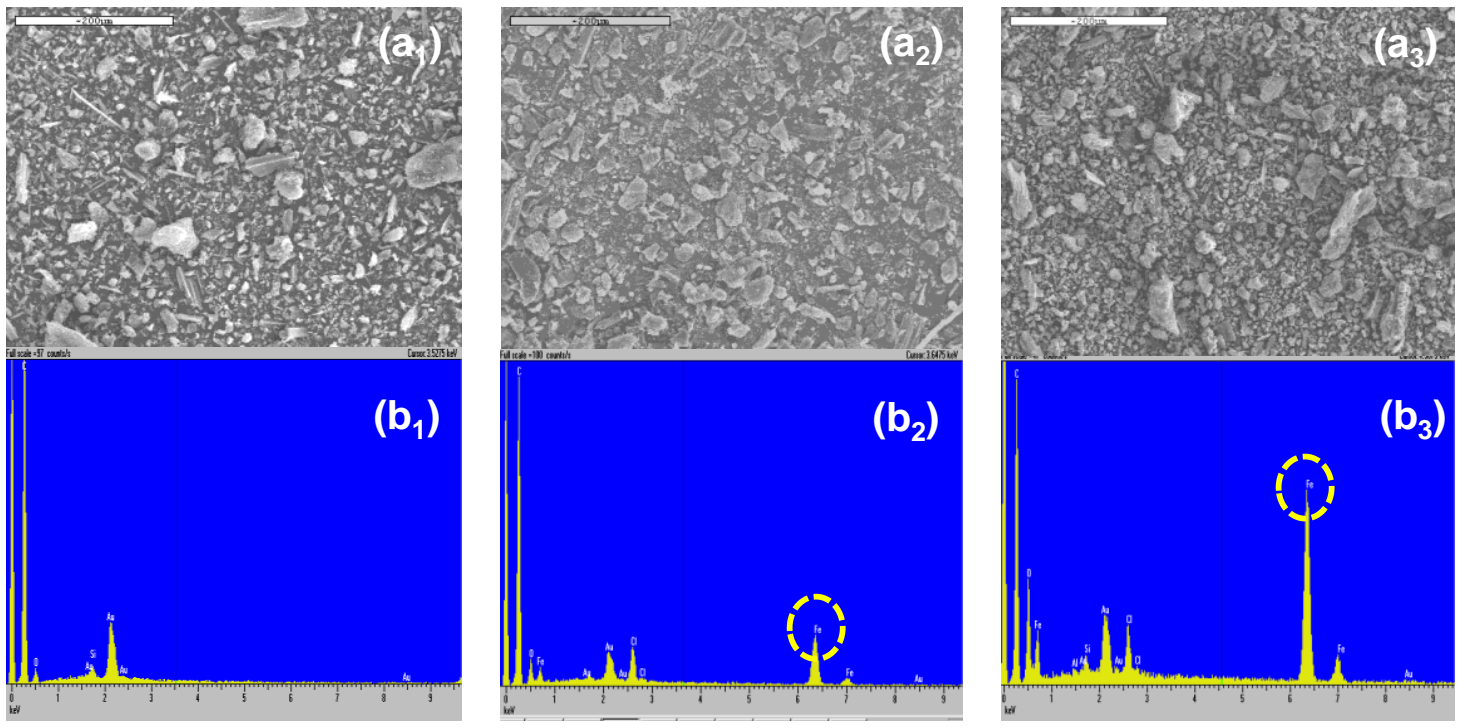

Figure 2. SEM images and EDS peaks of bare $\operatorname{PAC}\left(a_{1}, b_{1}\right), \operatorname{PAC} / \mathrm{Fe}(1)\left(a_{2}, b_{2}\right)$ and $\operatorname{PAC} / \mathrm{Fe}(3)\left(a_{3}, b_{3}\right)$

\subsection{Adsorption of DCF onto PAC/Fe adsorbents}

The adsorption rates of DCF onto bare PAC, and onto the four PAC/Fe adsorbents prepared, are shown in Fig. 3a. It was found that the adsorption of DCF on the adsorbents reached pseudo-equilibrium after approximately $120 \mathrm{~min}$. After the equilibrium period, the amount of adsorbed DCF did not significantly change with time (with an exception of PAC/Fe(2) adsorbent). The rate of DCF adsorption was decreased significantly in the case of composite adsorbents with high iron loading; however, the rate was higher in the case of $\mathrm{PAC} / \mathrm{Fe}(1)$ with the adsorption being much more substantial than that on bare PAC. Considering the hydrophobic character of DCF $\left(\log \mathrm{K}_{\mathrm{ow}}=4.51\right)$ and its rather negative charge $(\mathrm{pKa}<\mathrm{pH})$, the adsorption of DCF is probably governed by $\pi-\pi$ dispersive interactions with the two aromatic rings 
approaching the carbon surface and electrostatic attractive forces with the PAC/Fe composites (as evidenced by the higher $\mathrm{pH}_{\mathrm{pzc}}$ values). However, other possible mechanisms of adsorption may play a role, including hydrogen bonding, or even chemisorption interactions with the impregnated iron oxides (ferrihydrites). A preferential sorption of DCF onto the ferrihydrites is also possible (Park et al., 2015), although this effect is not supported by the results with PAC impregnated with excessive amounts of iron oxides [PAC/Fe(2)].
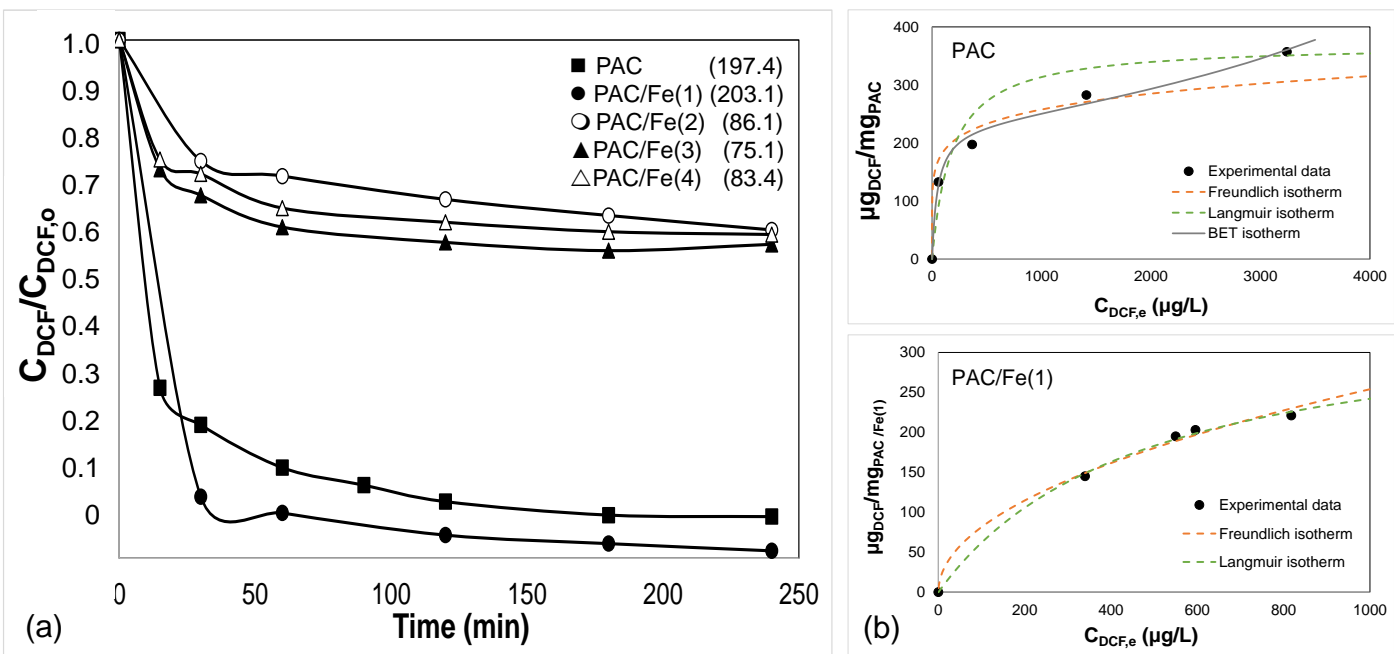

Figure 3. (a) Kinetics of DCF adsorption onto the adsorbents (inset: in brackets the amount ( $\mu \mathrm{g}$ ) of DCF adsorbed per mg of adsorbent), (b) non-linear fitting of Freundlich, Langmuir and BET isotherm models for PAC and PAC/Fe(1) adsorbents

The adsorption isotherms obtained by fitting the adsorbed amounts of DCF on the carbon surface (in units of $\mu \mathrm{g}_{\mathrm{DCF}} / \mathrm{mg}_{\mathrm{PAC}}$ ) and the equilibrium concentration $\left(\mathrm{C}_{\mathrm{DCF}, \mathrm{e}}\right)$ in aqueous solutions were interpreted using typical adsorption models for hydrophobic compounds; i.e., the Freundlich isotherm, which is an empirical relationship and is applied to non-ideal adsorption and the Langmuir isotherm which describes the concept of monolayer adsorption on energetically homogeneous surface (Fig. 3b). In the case of PAC, the BET isotherm developed by Ebadi et al. (2009) for liquid phase adsorption was also fitted to the experimental results. Table 2 shows the values of corresponding isotherm parameters and their correlation coefficients $\left(\mathrm{R}^{2}\right)$. BET isotherm seems to fit better the results of DCF adsorption on PAC, implying that a multilayer adsorption takes place onto bare PAC. On the other hand, the adsorption feature in the case of PAC/Fe(1) is caused by the monolayer adsorption of DCF, as evidenced by the better correlation with Langmuir model. Interestingly, the $1 / n$ values of the Freundlich model increased upon iron oxide impregnation. This indicates that sorption by $\mathrm{PAC} / \mathrm{Fe}(1)$ is relatively sensitive to the DCF concentration.

Table 2. Langmuir, Freundlich and BET isotherm parameters obtained by nonlinear fitting for the PAC and $\mathrm{PAC} / \mathrm{Fe}(1)$ adsorbents.

\begin{tabular}{lcccccccccc}
\hline \multirow{2}{*}{ Adsorbent } & \multicolumn{3}{c}{ Langmuir } & \multicolumn{3}{c}{ Freundlich } & \multicolumn{3}{c}{ BET } \\
\cline { 2 - 12 } & $\mathbf{K}_{\mathbf{L}}$ & $\mathbf{q}_{\mathbf{m}}$ & $\mathbf{R}^{\mathbf{2}}$ & $\mathbf{K}_{\mathbf{F}}$ & $\mathbf{1} / \mathbf{n}$ & $\mathbf{R}^{\mathbf{2}}$ & $\mathbf{K}_{\mathbf{s}}$ & $\mathbf{K}_{\mathbf{L}}$ & $\mathbf{q}_{\mathbf{m}}$ & $\mathbf{R}^{\mathbf{2}}$ \\
\hline PAC & 0.0055 & 370.37 & 0.984 & 94.45 & 0.145 & 0.832 & 0.0232 & 0.00012 & 232.12 & 0.993 \\
$\mathrm{PAC} / \mathrm{Fe}(1)$ & 0.0021 & 357.14 & 0.982 & 8.36 & 0.494 & 0.957 & - & - & - & - \\
\hline
\end{tabular}

\subsection{Homogeneous Fenton regeneration of PAC}

Fig. 4a shows the $\mathrm{H}_{2} \mathrm{O}_{2}$ concentration decay in saturated with DCF PAC dispersions for different iron salt $\left(\mathrm{FeSO}_{4} 7 \mathrm{H}_{2} \mathrm{O}\right.$ ) to $\mathrm{H}_{2} \mathrm{O}_{2}$ molar ratios. A complete $\mathrm{H}_{2} \mathrm{O}_{2}$ consumption is observed within 24 h due to Fenton reactions $\left(\mathrm{Fe}^{2+}+\mathrm{H}_{2} \mathrm{O}_{2} \rightarrow \mathrm{Fe}^{3+}+{ }^{\cdot} \mathrm{OH}+\mathrm{OH}^{-}\right)$, with the destruction kinetics being faster for higher $\mathrm{H}_{2} \mathrm{O}_{2}$ 
concentrations. The implementation of Fenton oxidation reactions is justified by the UV/Vis spectra (190 to $410 \mathrm{~nm}$ ) of samples collected during the experiments, which presented significant fluctuations in UV absorbance throughout the wavelength range with treatment time (Fig. 4b). Specifically, a widening and shifting of the two peaks at $210 \mathrm{~nm}$ and $276 \mathrm{~nm}$ to higher wavelengths were reported. It is noted that the fluctuations observed at $276 \mathrm{~nm}$ (characteristic wavelength of DCF) is not related to the presence of DCF in the solution (possibly due to DCF desorption from the PAC matrix) but rather to other organics (probably oxidation byproducts of the adsorbed DCF), as evidenced by the respective HPLC/DAD measurements (data not shown here).
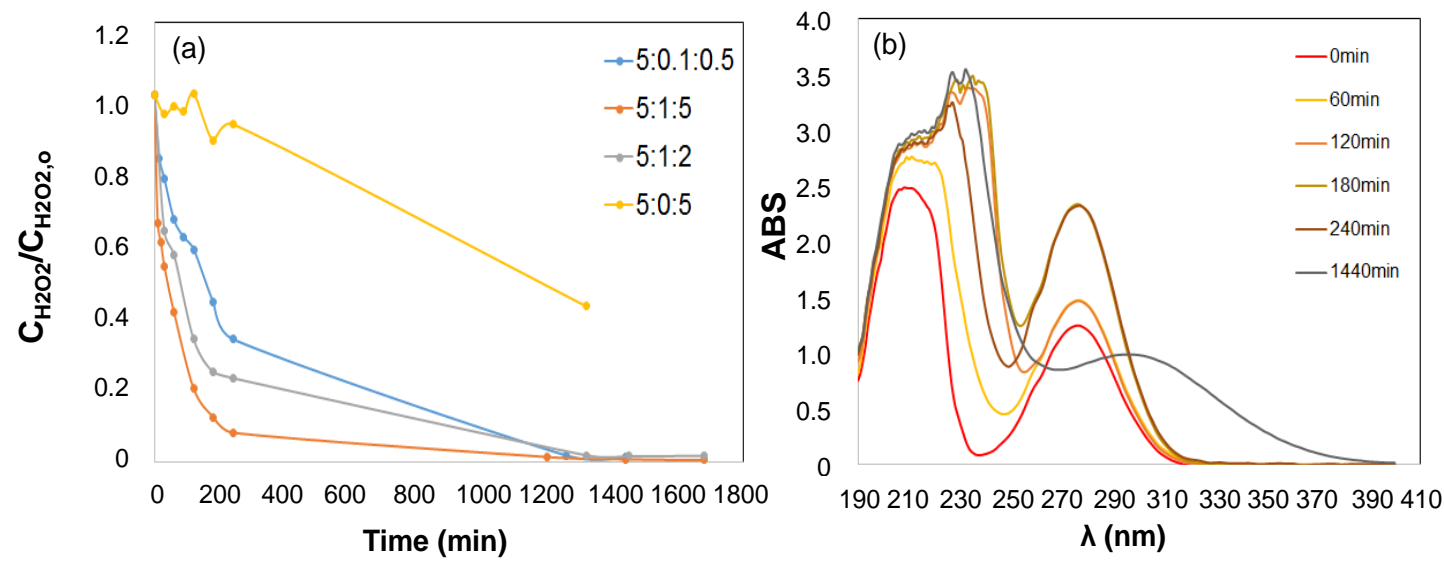

Figure 4. (a) Temporal variation of $\mathrm{H}_{2} \mathrm{O}_{2}$ concentration during the homogeneous Fenton treatment of saturated PAC (PAC:FeSO ${ }_{4} 7 \mathrm{H}_{2} \mathrm{O}: \mathrm{H}_{2} \mathrm{O}_{2}$ in $\mathrm{mg} \mathrm{l}^{-1}: \mathrm{mM}: \mathrm{mM}$ ), (b) UV spectra of samples collected at different electrolysis times (experimental conditions: $\mathrm{PAC} 5 \mathrm{mg} \mathrm{l}^{-1}$, $\mathrm{FeSO}_{4} 7 \mathrm{H}_{2} \mathrm{O} 0.1 \mathrm{mM}, \mathrm{H}_{2} \mathrm{O}_{2} 0.5 \mathrm{mM}, \mathrm{pH}$ 3.0)

The adsorption of DCF before and after the regeneration of PAC is shown in Fig. 5. The values reported correspond to the equilibrium reached after approximately $180 \mathrm{~min}$. The regeneration of saturated PAC with the single addition of $\mathrm{H}_{2} \mathrm{O}_{2}\left(\mathrm{PACr}_{\mathrm{eg}, 4}\right)$ was followed by a decreased DCF readsorption, implying that the specific PAC does not favour the catalytic decomposition of $\mathrm{H}_{2} \mathrm{O}_{2}$ into ${ }^{\circ} \mathrm{OH}$. In the case of the homogeneous Fenton regeneration, the best results were obtained for low concentrations of dissolved iron catalyst and $\mathrm{H}_{2} \mathrm{O}_{2}$ in the PAC solution ( $\mathrm{PACr}_{e, 1}$ ), with the respective loss in DCF adsorption capacity reaching $\sim 60 \%$.

\subsection{Heterogeneous Fenton regeneration of $P A C / F e(1)$}

Fig. 6 a shows the $\mathrm{H}_{2} \mathrm{O}_{2}$ concentration decay in saturated with DCF PAC/Fe(1) solutions for two different $\mathrm{H}_{2} \mathrm{O}_{2}$ concentrations ( 2.0 and $3.5 \mathrm{mM}$ ). It is clear that the decomposition of the dissolved $\mathrm{H}_{2} \mathrm{O}_{2}$ on the surface of the $\mathrm{PAC} / \mathrm{Fe}(1)$ presents low rates. This is not surprising considering that the heterogeneous Fenton reactions take place at neutral $\mathrm{pH}$, while the available iron to catalyze the decomposition of $\mathrm{H}_{2} \mathrm{O}_{2}$ ( $0.203 \mathrm{mg} \mathrm{Fe}$ in form of iron oxides) is rather minimum, in comparison to the homogeneous Fenton experiments ( $55.845 \mathrm{mg} \mathrm{Fe}$ in form of ferrous ions). However, oxidation reactions appear to have taken place within the $24 \mathrm{~h}$ stirring of the PAC/Fe(1) solution, as evidenced by the UV spectra depicted in Fig $6 \mathrm{~b}$, as well as the increased DCF adsorption efficiency on the regenerated adsorbent (Fig. 5). According to Fig. 5 , the presence of iron catalysts on the PAC surface is beneficial for achieving a higher regeneration efficiency by heterogeneous Fenton reactions, even at neutral pH. Moreover, an enhanced efficiency was observed when lower $\mathrm{H}_{2} \mathrm{O}_{2}$ concentrations were used for the regeneration of the composite material

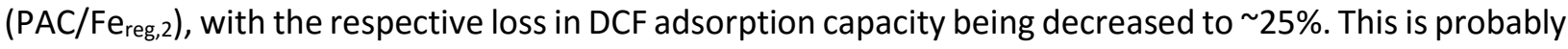
due to the significant oxidation of the composite material at harsher environments (higher $\mathrm{H}_{2} \mathrm{O}_{2}$ concentrations), as in the case of the homogeneous Fenton experiments. It is noted that an excellent 
stability of PAC/Fe(1) was observed during the regeneration, as evidenced by the negligible leaching of iron (data not shown here).

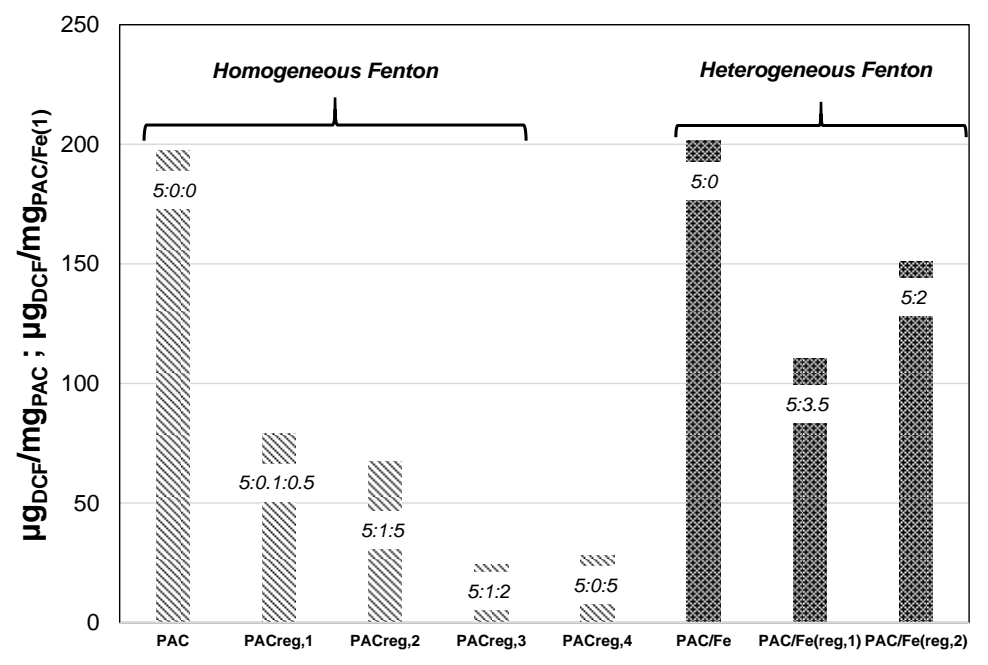

Figure 5. Amount of DCF adsorbed per unit mass of PAC or PAC/Fe(1) before and after their Fenton regeneration. The numbers on the bars correspond to the concentrations of the materials used

(homogeneous Fenton, PAC: $\mathrm{FeSO}_{4} 7 \mathrm{H}_{2} \mathrm{O}: \mathrm{H}_{2} \mathrm{O}_{2}$ in $\mathrm{mg} \mathrm{l}^{-1}$ : $\mathrm{mM}: \mathrm{mM}$;

heterogeneous Fenton, $\mathrm{PAC} / \mathrm{Fe}(1): \mathrm{H}_{2} \mathrm{O}_{2}$ in $\mathrm{mg}^{\left.l^{-1}: \mathrm{mM}\right)}$
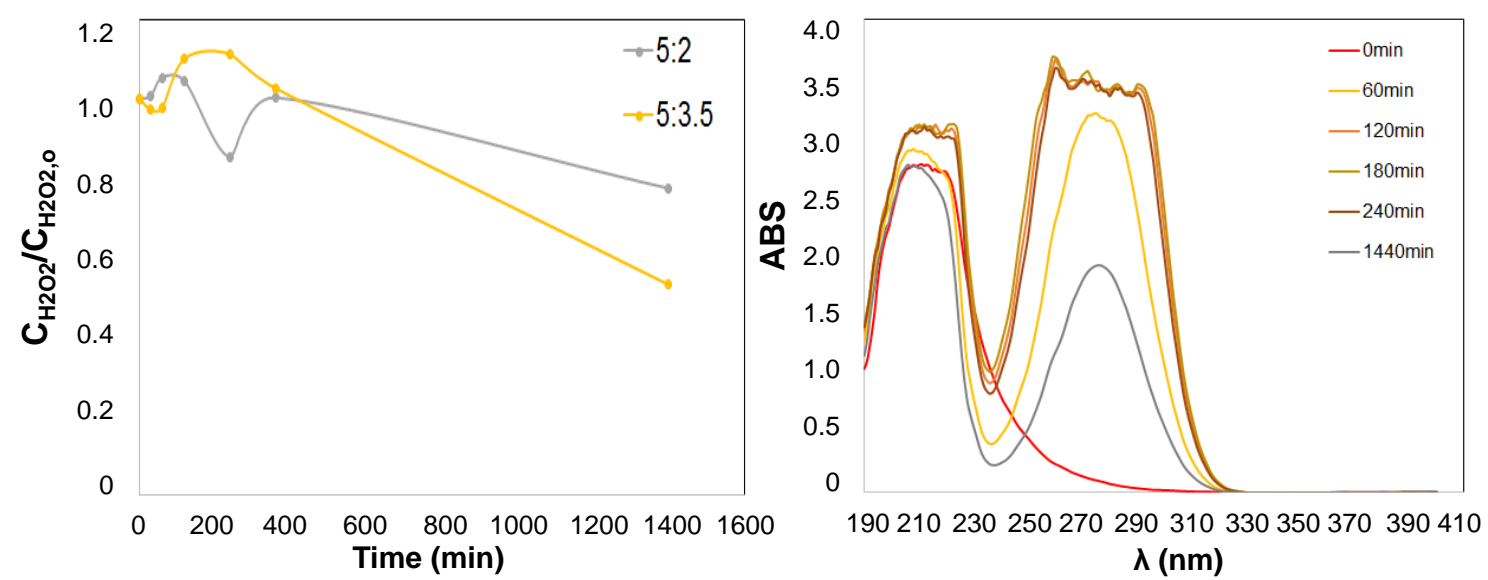

Figure 6. (a) Temporal variation of $\mathrm{H}_{2} \mathrm{O}_{2}$ concentration during the heterogeneous Fenton treatment of

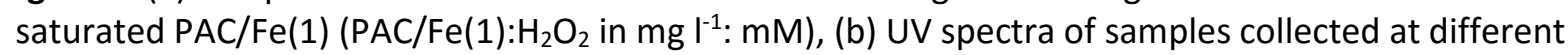
electrolysis times (experimental conditions: PAC/Fe(1) $5 \mathrm{mg} \mathrm{l}^{-1}, \mathrm{H}_{2} \mathrm{O}_{2} 2.0 \mathrm{mM}, \mathrm{pH} 7.45$ )

\subsection{Effect of $\mathrm{pH}$ on DCF adsorption}

Considering that Fenton oxidation may significantly alter the surface properties of the adsorbents, a set of batch adsorption experiments were performed by varying the solution $\mathrm{pH}$, before and after the regeneration operation. According to Table 3, the adsorption capacity of both PAC and PAC/Fe(1) adsorbents is strongly affected by the $\mathrm{pH}$, being greater at rather acidic environments. Specifically, at $\mathrm{pH}$ 4 , the adsorption capacity of the regenerated PAC was almost completely recovered, while the heterogeneous Fenton regeneration of PAC/Fe(1) resulted to an even larger DCF sorption efficiency in comparison to the first adsorption step. As $\mathrm{pH}$ decreases toward the pKa value of the DCF (4.15), $\mathrm{H}^{+}$ions as well as organic anions are adsorbed on the surface of the carbon materials. Since the concentration of 
$\mathrm{H}^{+}$rapidly exceeds that of the DCF anions, the former adsorb on the carbon surface far in excess of the anions and subsequently enhance anion adsorption. However, because the concentration of DCF anions decreases as $\mathrm{pH}$ increases, a point of diminishing returns is eventually reached and a maximum in adsorption uptake is observed. This phenomenon may be strongly affected by the surface charge of the two adsorbents, which in turn can be altered as a consequence of their Fenton oxidation. Considering the harsher oxidation environment during the homogeneous Fenton oxidation of the PAC, it is expected that a significant decrease of its $\mathrm{pH}_{\mathrm{pzc}}$ value may have taken place, thus decreasing its positive surface charge, and therefore, the electrostatic attractions with the negatively charged DCF molecules. In turn, a marginal decrease of the $\mathrm{pH}_{\mathrm{pzc}}$ value of $\mathrm{PAC} / \mathrm{Fe}(1)$ is assumed to have taken place.

Table 3. Effect of $\mathrm{pH}$ on DCF adsorption on PAC and PAC/Fe(1) adsorbents (in mg DCF per g adsorbent) before and after their Fenton regeneration.

\begin{tabular}{|c|c|c|c|c|c|c|}
\hline \multirow{2}{*}{ Adsorbent } & \multicolumn{3}{|c|}{ Before } & \multicolumn{3}{|c|}{ After } \\
\hline & pH 7.3 & pH 6 & pH 4 & pH 7.3 & pH 6 & pH 4 \\
\hline PAC $^{a}$ & 311.9 & 398.7 & 761.2 & 37.4 & 199.3 & 727.4 \\
\hline $\mathrm{PAC} / \mathrm{Fe}(1)^{\mathrm{b}}$ & 330.0 & 379.9 & 738.3 & 254.1 & 341.9 & 804.7 \\
\hline
\end{tabular}

${ }^{a}$ Experimental conditions: PAC $20 \mathrm{mg} \mathrm{l}^{-1}$, DCF $20 \mathrm{mg} \mathrm{l}^{-1}, \mathrm{Fe}_{2} \mathrm{SO}_{4} 7 \mathrm{H}_{2} \mathrm{O} 1 \mathrm{mM}, \mathrm{H}_{2} \mathrm{O}_{2} 5 \mathrm{mM}$; ${ }^{\text {b Experimental }}$ conditions: PAC $20 \mathrm{mgl}^{-1}$, DCF $20 \mathrm{mgl}^{-1}, \mathrm{H}_{2} \mathrm{O}_{2} 5 \mathrm{mM}$.

\section{Conclusions}

This study demonstrates the attributes of the Fenton oxidation process for the efficient regeneration of powdered activated carbon employed for the removal of hydrophobic organic micropollutants from drinking water. Batch experiments with the pharmaceutical diclofenac revealed the benefits of the heterogeneous over the homogeneous Fenton treatment of saturated PAC. The regeneration efficiency was found to be the outcome of a complicated interplay between the modification of both textural and chemical surface properties of the activated carbons, the feed solution properties $\left(\mathrm{H}_{2} \mathrm{O}_{2}, \mathrm{pH}\right)$ and the quantity and the nature of the iron species impregnated on the PAC (depending on the iron-impregnation procedure applied). The preparation of a ferrihydrite-PAC with low iron loading proved to be a promising adsorbent-catalyst material for the removal of organic compounds from water. Research is ongoing in this laboratory along two lines: i.e. material optimization and testing in a novel hybrid process scheme developed by the authors, involving a continuous Fe/PAC - Fenton process in conjunction with a low pressure membrane separation process.

\section{Acknowledgments}

The authors wish to thank Dr. Stella Sklari, Laboratory of Inorganic Materials (LIM- CPERI/CERTH) for her valuable assistance in the synthesis of PAC/Fe composite materials, and the personnel of Analytical Services Unit (ASUCPERI/CERTH) for analytical support. This research was financially supported by the General Secretariat for Research and Technology, Greek Ministry of Culture, Education and Religious Affairs, through the programme EPAN-II/ESPA "Bilateral R\&D Cooperation between Greece and Israel 2013-2015", project No. ISR_3387. Partners in this project include TEMAK S.A, Thessaloniki, the Rabin Desalination Laboratory at the TECHNION Israel Institute of Technology and the Israel national water company, MEKOROT.

\section{References}

Anfruns A., Montes-Morán M.A., Gonzalez-Olmos R. and Martin M.J. (2013), $\mathrm{H}_{2} \mathrm{O}_{2}$-based oxidation processes for the regeneration of activated carbons saturated with volatile organic compounds of different polarity, Chemosphere, 91, 48-54.

Bach A. and Semiat R. (2011), The role of activated carbon as a catalyst in $\mathrm{GAC} /$ iron oxide $/ \mathrm{H}_{2} \mathrm{O}_{2}$ oxidation process, Desalination, 273, 57-63. 
Brillas E., Sirés I. and Oturan M.A. (2009), Electro-Fenton process and related electrochemical technologies based on Fenton's reaction chemistry, Chemical Reviews, 109, 6570-6631.

Bañuelos J.A., Rodríguez F.J., Rocha J.M., Bustos E., Rodríguez A., Cruz J.C., Arriaga L.G. and Godínez L.A. (2013) Novel electro-Fenton approach for regeneration of activated carbon, Environmental Science \& Technology, 47, 7927-7933.

Clark M.M., Baudin I. and Anselme C. (1996), Membrane-Powdered Activated Carbon Reactors, in Water Treatment, Membrane Processes, AWWA Research Foundation, Lyonnaise des Eaux, Water Research Commission of South Africa, McGraw Hill, New York.

Do M.H., Phan N.H., Nguyen T.D., Suong Pham T.T., Nguyen V.K., Trang Vu T.T. and Phuong Nguyen T.K. (2011), Activated carbon/ $\mathrm{Fe}_{3} \mathrm{O}_{4}$ nanoparticle composite: Fabrication, methyl orange removal and regeneration by hydrogen peroxide, Chemosphere, 85, 1269-1276.

Ebadi A., Soltan Mohammadzadeh J.S. and Khudiev A. (2009), What is the correct form of BET isotherm for modeling liquid phase adsorption? Adsorption, 15, 65-73.

Horng R.S. and Tseng I-C. (2008), Regeneration of granular activated carbon saturated with acetone and isopropyl alcohol via a recirculation process under $\mathrm{H}_{2} \mathrm{O}_{2}$ /UV oxidation, Journal of Hazardous Materials, 154, 366-372.

Kan E. and Huling S.G. (2009), Effects of temperature and acidic pre-treatment on Fenton-driven oxidation of MTBEspent granular activated carbon, Environmental Science and Technology, 43, 1493-1499.

Lapworth D.J., Baran N., Stuart M.E. and Ward R.S. (2012), Emerging organic contaminants in groundwater: A review of sources, fate and occurrence, Environmental Pollution,163, 287-303.

Loos R., Gawlik B.M., Locoro G., Rimaviciute E., Contini S. and Bidoglio G., EU-wide survey of polar organic persistent pollutants in European river waters, Environmental Pollution, 157, 561-568.

Oller I., Malato S. and Sánchez-Pérez J.A. (2011), Combination of Advanced Oxidation Processes and biological treatments for wastewater decontamination-A review, Science of the Total Environment, 409, 4141-4166.

Park H-S., Koduru J.R., Choo K-H. and Lee B. (2015), Activated carbons impregnated with iron oxide nanoparticles for enhanced removal of bisphenol A and natural organic matter, Journal of Hazardous Materials, 286, 315-324.

Patsios S.I. and Karabelas A.J. (2011), An investigation of the long-term filtration performance of a Membrane Bioreactor (MBR): the role of specific organic fractions, Journal of Membrane Science, 372, 102-115.

Plakas K.V., Karabelas A.J., Sklari S.D. and Zaspalis V.T. (2013), Toward the development of a novel electro-fenton system for eliminating toxic organic substances from water. Part 1. in situ generation of hydrogen peroxide, Industrial \& Engineering Chemistry Research, 52, 13948-13956.

Salvador F., Martin-Sanchez N., Sanchez-Hernandez R., Sanchez-Montero M.J. and Izquierdo C. (2015) Regeneration of carbonaceous adsorbents. Part II: Chemical, Microbiological and Vacuum Regeneration, Microporous and Mesoporous Materials, 202, 277-296.

Sarasidis V.C., Plakas K.V., Patsios S.I. and Karabelas A.J. (2014), Investigation of diclofenac degradation in a continuous photo-catalytic membrane reactor. Influence of operating parameters, Chemical Engineering Journal, 239, 299-311.

Sklari S.D., Plakas K.V., Petsi P.N., Zaspalis V.T. and Karabelas A.J. (2015), Toward the development of a novel electroFenton system for eliminating toxic organic substances from water. Part 2. Preparation, characterization, and evaluation of iron-impregnated carbon felts as cathodic electrodes, Industrial \& Engineering Chemistry Research, 54, 2059-2073.

Stoquart C., Servais P., Bérubéc P.R. and Barbeau B. (2012), Hybrid membrane processes using activated carbon treatment for drinking water: A review, Journal of Membrane Science, 411-412, 1-12.

Wang L. and Balasubramanian N. (2009), Electrochemical regeneration of granular activated carbon saturated with organic compounds, Chemical Engineering Journal, 155, 763-768.

Weng C-H. and Hsu M-C. (2008), Regeneration of granular activated carbon by an electrochemical process, Separation and Purification Technology, 64, 227-236.

Zanella O., Tessaro I.C. and Féris L.A. (2014), Desorption- and decomposition-based techniques for the regeneration of activated carbon, Chemical Engineering \& Technology, 37, 1447-1459. 